\title{
ANALISA KEBISINGAN AKIBAT AKTIVITAS TRANSPORTASI \\ DI JALAN AHMAD YANI \\ KOTA SORONG
}

\author{
Hendrik Pristianto
}

Dosen Program Studi Teknik Sipil Universitas Muhammadiyah Sorong

\begin{abstract}
ABSTRAK
Kebisingan merupakan polusi suara yang didefinisikan sebagai bunyi yang tidak diinginkan dari usaha atau kegiatan dalam tingkat dan waktu tertentu yang dapat menimbulkan gangguan kesehatan dan kenyamanan lingkungan. Kebisingan dari jalan raya berasal dari kendaraan berat (HV), kendaraan ringan $(L V)$ dan sepeda motor $(M C)$. Penelitian ini bertujuan untuk mengetahui tingkat kebisingan yang terjadi pada ruas Jalan Ahmad Yani dengan pengambilan data langsung di lapangan berupa data kebisingan serta beberapa variabel lalu lintas lainnya seperti volume dan kecepatan kendaraan. Data di analisis dengan menggunakan rumus hitung Leq serta dengan perhitungan secara empiric dengan pendekatan rumus BNL untuk mendapatkan nilai kebisingan pada dua titik lokasi yang ditinjau. Pengambilan data dilakukan siang dan malam sehingga diketahui tingkat kebisingan pada malam hari yaitu 41,67\%. kurang signifikan dibanding siang hari sebesar 58,33\% dengan Berdasarkan hasil analisis didapatkan nilai kebisingan dalam Leq hitung paling tinggi sebesar 68,12 dBA sedangkan dalam pendekatan rumus BNL nilai kebisingan tertinggi yaitu 69,36 dBA. Dengan nilai kebisingan tersebut Hasil penelitian menunjukkan bahwa ruas Jalan Ahmad Yani dengan dua titik lokasi yang berbeda telah melebihi batas standar kebisingan yang diijinkan menurut Keputusan Menteri Negara Lingkungan Hidup No.48 tahun 1996 tentang baku mutu kebisingan. Sehingga perlu di upayakan peredam kebisingan (noise barrier) baik peredam kebisingan alami berupa penanaman pohon maupun peredam kebisingan buatan.
\end{abstract}

Kata Kunci : Kebisingan, Decibel, Sound Level Meter, Noise Barrier, Lalu Lintas. 


\section{PENDAHULUAN}

\subsection{Latar Belakang}

Kecenderungan peningkatan jumlah kendaraan bermotor yang beroperasi, akan menambah beban lalu lintas dan menimbulkan berbagai permasalahan yang dapat mengganggu sebagian besar masyarakat perkotaan. Sebagai salah satu contohnya yaitu meningkatnya intensitas polusi suara berupa kebisingan bagi lingkungan di sekitar jalan tersebut. Sumber bising lalu lintas jalan diantaranya berasal dari kendaraan bermotor baik roda dua, roda empat maupun kendaraan berat yang sumber penyebab bisingnya antara lain dari bunyi klakson kendaraan, suara knalpot akibat penekanan pedal gas secara berlebihan dan penggunaan knalpot racing, Tiap-tiap kendaraan menghasilkan kebisingan, namun sumber dan besarnya dari kebisingan dapat sangat bervariasi tergantung jenis kendaraan.

Sepanjang Jalan Ahmad Yani yang menjadi objek penelitian merupakan ruas jalan yang berdekatan dengan banyak sarana umum, pemukiman penduduk, sarana pendidikan dan kesehatan serta tempat ibadah yang berhadapan langsung dengan jalan. Jalan Ahmad Yani merupakan jalan yang volume lalu lintasnya cukup padat juga kecepatan kendaraan yang lumayan tinggi, terutama bila masuk saat-saat jam sibuk yang memungkinkan terjadinya kenaikan intensitas polusi suara.

Untuk itu berdasarkan latar belakang masalah yang telah dijabarkan diatas maka penulis melakukan penelitian sebagai bahan Skripsi dengan Judul "Analisa Kebisingan Akibat Aktivitas Transportasi Di Jalan Ahmad Yani Kota Sorong”.

\subsection{Batasan Masalah}

Dalam penyusunan Skripsi ini, terdapat batasan ruang lingkup pembahasan agar tidak menyimpang dari permasalahan dan mudah dimengerti. Sesuai judul yang di kemukakan, maka pembahasan dalam studi analisa ini adalah sebagai berikut :
1. Mengukur tingkat kebisingan yang berasal dari suara kendaraan di Jalan Ahmad Yani

2. Dalam pembahasan penulis menggunakan Standar baku Mutu berdasarkan Keputusan Menteri Negara Lingkungan Hidup Kep48/MENLH/11/1996,tanggal

Nopember 1996.

\subsection{Tujuan Penelitian}

Adapun tujuan dari penelitian ini adalah :

1. Untuk mengetahui bagaimana tingkat kebisingan dari suara kendaraan yang melintasi Jalan Ahmad Yani Kota Sorong

2. Untuk mengetahui apakah tingkat kebisingan pada ruas yang di tinjau telah memenuhi standar baku mutu berdasarkan Keputusan Menteri Negara Lingkungan Hidup Kep48/MENLH/11/1996

3. Untuk mengetahui sumber kebisingan lalu lintas dari Jalan Ahmad Yani

\section{LANDASAN TEORI}

\section{Tentang Kebisingan}

Semua bunyi yang mengalihkan perhatian, menganggu, atau berbahaya bagi kesehatan sehari-hari ( kerja, istirahat, hiburan, atau belajar ) di anggap sebagai bising. ( Doelle L.L.,1993 )

Menurut Bridger, (dalam Yadat T.,2014) kebisingan biasanya didefinisikan sebagai suara atau suara pada amplitudo tertentu yang dapat menyebabkan kejengkelan atau mengganggu komunikasi. Suara dapat diukur secara objektif sedangkan kebisingan merupakan fenomena yang subjektif.

Menurut Keputusan Menteri Negara Lingkungan Hidup No. KEP48/MENLH/11/1996 definisi bising adalah bunyi yang tidak diinginkan dari usaha atau kegiatan dalam tingkat dan waktu tertentu yang dapat menimbulkan gangguan 
kesehatan dan kenyamanan lingkungan. Menurut menteri kesehatan Republik Indonesia bahwa bising adalah semua suara yang tidak dikehen daki yang bersumber dari alat-alat produksi dan atau alat-alat kerja yang pada tingkat tertentu dapat menimbulkan gangguan pendengaran. Kebisingan adalah semua bunyi atau suara yang tidak dikehendaki yang dapat mengganggu kesehatan dan keselamatan. Satuan dari kebisingan adalah decibell (dB).

Tabel 1. Kriteria Batas Kebisingan menurut KEP.48/MENLH/II/1996

\begin{tabular}{|c|l|c|}
\hline No & \multicolumn{1}{|c|}{ Peruntukan } & $\begin{array}{c}\text { Tingkat } \\
\text { Kebisingan } \\
(\mathbf{d B})\end{array}$ \\
\hline 1. & Perumahan dan & 55 \\
2. & Pemukiman & 70 \\
3. & Perdagangan & 65 \\
4. & Perkantoran & 50 \\
5. & Ruang terbuka hijau & 70 \\
6. & Industri & 60 \\
7. & Pemerintahan & 70 \\
8. & Rekreasi & 55 \\
9. & Rumah Sakit & 55 \\
10. & Sekolah & 55 \\
& Tempat Ibadah & \\
\hline
\end{tabular}

Sumber : Kep. Menteri Negara Lingkungan Hidup, 1996

Nilai $\mathrm{L}_{\mathrm{eq}}$ yang dihitung dibandingkan dengan nilai baku tingkat kebisingan yang ditetapkan dengan toleransi $+3 \mathrm{~dB}(\mathrm{~A})$.

\section{Sifat dan Sumber Kebisingan}

\section{A. Sifat Bising}

Menurut Goembira, (dalam Yadat T.,2014) Sifat dari kebisingan antara lain :

1. Kadarnya berbeda.

2. Jumlah tingkat bising bertambah, maka gangguan akan bertambah pula.

3. Bising perlu dikendalikan karena sifatnya mengganggu.

B. Sumber Bising

Menurut Doelle, (2013) sumber bising utama dalam pengendalian bising lingkungan dapat di klasifikasikan dalam 2 kelompok,yaitu :
1. Bising interior, sumber bising yang paling sering dibuat oleh manusia, alatalat rumah tangga atau mesin-mesin gedung.

2. Bising luar (outdoor), berasal dari lalu lintas, transportasi, industri, alat-alat mekanis yang terlihat dalam gedung, tempat pembangunan gedung-gedung, perbaikan jalan, kegiatan olahraga dan lain-lan di luar gedung. Bising transportasi termasuk kendaraan transportasi darat seperti truk, bus, mobil dan sepeda motor.

\section{Zona Kebisingan}

Dalam Peraturan Menteri Kesehatan Republik Indonesia No. 718/Men/Kes/Per/XI/1987, tentang kebisingan yang berhubungan dengan kesehatan dibagi dalam 4 zona sebagai berikut :

Tabel 2. Pembagian Zona Bising Oleh Menteri Kesehatan

\begin{tabular}{|c|c|c|}
\hline No & Zona & $\begin{array}{c}\text { Tingkat } \\
\text { Kebisingan yang } \\
\text { dianjurkan }\end{array}$ \\
\hline 1 & $\mathrm{~A}$ & $35-45 \mathrm{~dB}$ \\
\hline 2 & $\mathrm{~B}$ & $45-55 \mathrm{~dB}$ \\
\hline 3 & $\mathrm{C}$ & $50-60 \mathrm{~dB}$ \\
\hline 4 & $\mathrm{D}$ & $60-70 \mathrm{~dB}$ \\
\hline
\end{tabular}

Sumber : (Sam F.,2012)

Keterangan :

Zona A : Tempat penelitian, rumah sakit, tempat perawatan kesehatan ,dsb;

Zona B : Perumahan, tempat pendidikan, rekreasi, dan sejenisnya;

Zona C : Perkantoran, Perdagangan, Pasar, dan sejenisnya;

Zona D : Industri, Pabrik, Stasiun Kereta Api, Terminal Bis, dan sejenisnya;

\section{Kebisingan Kendaraan Bermotor}

Menurut White dan Walker, (dalam Leonard F.,2014) kebisingan oleh kendaraan bermotor berasal dari beberapa sumber, yaitu 
mesin, transmisi, rem, klakson, knalpot dan gesekan roda dengan jalan.

Kebisingan akibat gesekan roda dengan jalan tergantung pada beberapa faktor, jenis ban, kecepatan kendaraan, kondisi permukaan jalan, dan kemiringan jalan. Kecepatan kendaraan mempengaruhi kebisingan yang dimunculkan akibat gesekan ban kendaraan dengan permukaan jalan, seperti jalan yang tidak halus dan basah, akan menimbulkan kebisingan yang lebih tinggi akibat terjadinya gesekan yang lebih hebat antara ban dengan permukaan jalan.

\section{Karakteristik Kendaraan Bermotor}

a) Kendaraan berat (HV)

Kendaraan berat adalah kendaraan bermotor dengan lebih dari 4 roda meliputi bis, truk 2 as, truk 3 as, dan truk kombinasi

b) Kendaraan ringan (LV)

Kendaraan ringan adalah kendaraan bermotor ber as dua dengan empat roda dan dengan jarak as 2,0-3,0 m. Kendaraan ini meliputi mobil penumpang, microbus, pick up, dan truk kecil.

c) Sepeda motor (MC)

Kendaraan bermotor dengan 2 atau 3 roda, meliputi sepeda motor dan kendaraan roda 3.

d) Kendaraan tak bermotor (UM)

Kendaraan dengan roda yang digerakkan oleh manusia atau hewan, meliputi sepeda, becak, kereta kuda, dan kereta dorong.

\section{Hubungan Volume Lalu Lintas - Kebisingan \\ Volume lalu lintas (Q) terhadap} kebisingan sangat berpengaruh, hal ini bisa di pahami karena tingkat kebisingan lalu lintas merupakan harga total dari beberapa tingkat kebisingan dimana masing-masing jenis kendaraan mempunyai tingkat kebisingan yang berbeda-beda.
Volume dihitung dengan menggunakan rumus sebagai berikut : (Yusniar W. O., 2014)

$\mathrm{Q}_{\text {total kendaraan }}=\mathrm{nLV}+\mathrm{nHV}+\mathrm{nMC}$

$\mathrm{P}_{\text {Jenis Kendaraan }}$

$(\mathrm{LV}, \mathrm{HV}, \mathrm{MC})=\frac{\text { Jenis Kendaraan }}{\text { Qtotal Kend } / \mathrm{Jam}} \times 100 \%$

Kecepatan dihitung menggunakan dengan menggunakan rumus sebagai berikut :

$\mu$
$\mu_{S}=\left(\frac{3.6 \times n \times d}{\sum_{l=1}^{n} t_{i}}\right)^{(3)}$
$V=\frac{\left(V_{L V \cdot n L V}\right)+\left(V_{H V \cdot n H V}\right)+\left(V_{M C \cdot n M C}\right)}{n L V+n H V+n M C}$

Dimana :

$\mathrm{Q}=$ Volume Lalu Lintas

$\mathrm{P} \quad=$ Persentasi (\%)

$\mu \mathrm{s} \quad=$ Kecepatan ruang tiap jenis kendaraan $(\mathrm{km} / \mathrm{jam})$

$\mathrm{n}=$ Jumlah Kendaraan (kend/jam)

$\mathrm{d}=\operatorname{Jarak}(\mathrm{m})$

$3.6=$ Konversi satuan $(\mathrm{jarak} / \mathrm{waktu})$ $(\mathrm{km} / \mathrm{jam})$

$t_{i} \quad=$ Jarak Tempuh (detik)

$\mathrm{V}=$ Kecepatan rata-rata kendaraan $(\mathrm{km} / \mathrm{jam})$

\section{Perhitungan Leq Kebisingan}

Pengambilan data kebisingan pada cara sederhana dilakukan oleh 2 orang dengan sebuah Sound Level Meter biasa diukur tingkat tekanan bunyi sesaat $\mathrm{dB}$ (A) selama 10 menit untuk tiap pengukuran. Pembacaan dilakukan setiap 5 detik Leq (10 menit) yang mewakili interval waktu tertentu, sehingga didapat 120 data. Kemudian data tersebut diolah untuk mendapatkan data tingkat kebisingan equivalen dengan menggunakan rumus berikut :

$L_{e q}=10 \log \left[\frac{1}{T} \sum_{i=1}^{n}\left(t_{i} \times 10^{\frac{L i}{10}}\right)\right]$

Dimana :

$\mathrm{L}_{\mathrm{eq}} \quad=$ Nilai kebisingan equivalen 
$\mathrm{T}=$ Total periode waktu pencatatan (600 detik)

$\mathrm{n} \quad=$ Banyaknya pencatatan data (120 data)

$\mathrm{t}_{\mathrm{i}} \quad=$ Periode waktu pencatatan (5 detik)

$\mathrm{L}_{\mathrm{i}} \quad=$ Nilai hasil pembacaan

Rumus di atas dapat disederhanakan menjadi:

$L_{e q}=10 \operatorname{loq}\left[\frac{1}{N} \sum_{i=1}^{n}\left(10^{\frac{L i}{10}}\right)\right]$

Dimana :

$\mathrm{N} \quad=$ Banyaknya data (600 detik/ 5 detik)

$\mathrm{L}_{\mathrm{eq}}$ adalah tingkat kebisingan equivalen yang menunjukan suatu nilai yang memperhitungkan intensitas suara total selama periode waktu tertentu dari tingkat suara yang berbeda-beda dari waktu ke waktu, tingkat kebisingan equivalen atau Leq adalah skala logaritmik yang nilai-nilainya dalam satuan desibel $(\mathrm{dB})$ yang tidak dapat ditambahkan langsung.

Basic Noise Level (BNL) adalah mengukur tingkat kebisingan puncak pada suatu lokasi yang penjumlahan dan besaran nilai kebisingan di pengaruhi oleh volume total kendaraan $(\mathrm{Q})$.

Menurut Murwono, (dalam Yusniar W. O.,2014) Perhitungan tingkat kebisingan secara empirical adalah sebagai berikut :

Kebisingan Basic Noise Level (BNL) :

$\mathrm{L} 10=42,2+10 \log \mathrm{Q}$

Keterangan :

$\begin{aligned} \mathrm{L}_{10} & =\text { Tingkat kebisingan dasar untuk } \\ & \text { tiap 1 jam (dBA) } \\ \mathrm{Q} & =\text { Arus lalu lintas (kend/jam) }\end{aligned}$

\section{METODOLOGI PENELITIAN}

\section{Lokasi Penelitian dan Waktu Penelitian}

\section{a. Lokasi Penelitian}

Dalam penelitian ini dipilih ruas jalan sesuai fungsi jalan yakni jalan arteri. Lokasi penelitian terletak sepanjang Jalan Ahmad Yani dari arah Kantor Telkom sampai Depan
Yohan. Seksi jalan yang dipakai survai adalah sepanjang \pm 600 meter.

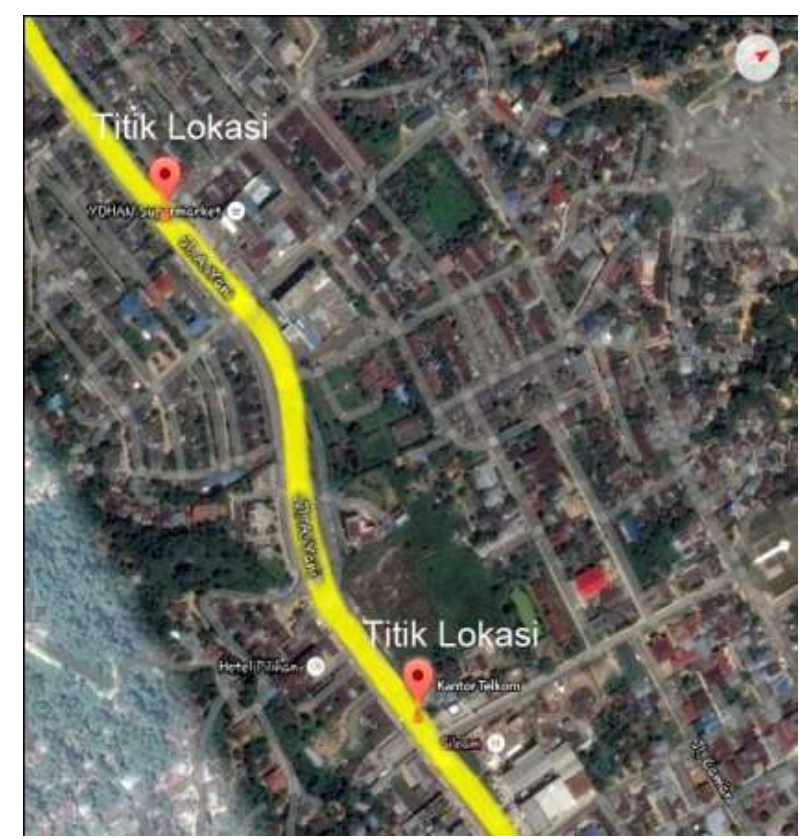

Gambar 1. Peta Lokasi Jalan Ahmad Yani Sumber: (google maps)

b. Waktu Penelitian

Waktu penelitian dilakukan selama 2 minggu. Pelaksanaan survei untuk pengumpulan data adalah pada hari SeninSabtu. Penelitian dilakukan pada jam-jam sibuk dimulai dari pukul 07.00- 20.00 WIT.

\section{Tahapan Pengumpulan Data}

a. Jenis Data

Jenis data yang digunakan dalam penelitian ini adalah data primer. Adapun data primer yang didapat dalam penelitian ini berupa observasi dan dokumentasi.

\section{b. Metode Pengambilan Data}

Penelitian ini dilakukan dengan pengamatan langsung dilapangan menggunakan alat pengukur kebisingan Sound Level Meter (SLM). Proses pengukuran dapat dilihat di bawah ini :

1) Meletakkan alat yang telah dipasangkan pada tripod dengan jarak $5 \mathrm{~m}$ dari tepi jalan. 
2) Alat di pasangkan pada tripod dan di tempatkan pada posisi 1,2 meter dari atas permukaan tanah.

3) Pengukuran dilakukan selama 10 (sepuluh) menit pada masing-masing interval dan pembacaan di lakukan setiap 5 (lima) detik.

4) Obyek penelitian di ambil dari dua titik yang menjadi sampel,sebagai berikut :

a. Depan Kantor Telkom, lokasi titik penelitian L1.

b. Jalan Sekitar Supermarket Yohan, lokasi titik penelitian L2.

\section{Data Volume Lalu Lintas}

Pengumpulan data volume lalu lintas atau banyaknya kendaraan yang lewat pada suatu garis pengamatan dilakukan dengan cara manual yaitu dengan alat hitung manual (counter). Setiap kendaraan yang lewat pada garis pengamatan di hitung dengan alat ini. Hitungan di ambil untuk setiap interval waktu 10 menit. Di gunakan tiga buah alat hitung manual per arah masing-masing untuk menghitung tiap jenis kendaraan yang di amati yaitu kendaraan sepeda motor atau roda dua (MC), kendaraan ringan ( $\mathrm{LV})$, dan kendaraan berat $(\mathrm{HV})$.

\section{Perhitungan Kecepatan Rata-Rata}

Pelaksanaan survei dilakukan secara manual, yaitu kecepatan dihitung berdasarkan waktu tempuh pada jarak tertentu. Alat yang di gunakan adalah stopwach dan radio HT. Pengambilan data kecepatan dilakukan oleh 2 orang yang masing-masing akan berada pada kedua titik sampel. Orang pertama memegang stopwach untuk mengukur waktu tempuh kendaraan yang melintas dari titik 0 sampai titik 50 meter .

Orang pertama memberi aba-aba saat kendaraan mulai melintas berjalan dari titik 0 , dan orang kedua pada titik $50 \mathrm{~m}$ memberi aba-aba saat kendaraan telah melewati titik 50 meter. Kemudian data tersebut di konversi ke satuan km/jam.

\section{PEMBAHASAN Analisa Data Kebisingan}

Pengambilan data dilakukan selama 8 jam pada jam-jam sibuk mulai dari pukul 07.00 WIT sampai 20.00 WIT. Pengambilan data dilakukan selama 2 (dua) minggu yaitu pada tanggal 11, 12, 13, 14, 15, 16, 18, 19 ,20, 21, 22, dan 23 Januari 2016. Dalam 1 jam didapatkan 120 data kebisingan dan dalam 1 hari (hitungan 8 jam pengambilan data) didapatkan 960 data kebisingan. Pengambilan data dilakukan pada sisi kiri dan kanan jalan dengan hasil rata-rata di masukkan kedalam rumus untuk mencari nilai kebisingan ekuivalen dan rumus Basic Noise Level (BNL) untuk mengukur tingkat kebisingan puncak yang dipengaruhi oleh volume kendaraan pada ruas Jalan Ahmad Yani.

\section{Perhitungan Volume Kendaraan}

Dari hasil penelitian data volume kendaraan, puncak jumlah kendaraan tertinggi yang melintas di area Jalan Ahmad Yani dapat dilihat pada tabel berikut.

Tabel 3. Puncak Hasil

PerhitunganVolume KendaraanTertinggi

\begin{tabular}{|c|c|c|c|c|c|}
\hline \multicolumn{2}{|c|}{ Waktu } & \multirow{2}{*}{$\begin{array}{c}\text { Q Total } \\
\text { Kendaraan } \\
\text { (per-jam) }\end{array}$} & \multirow[b]{2}{*}{ LV(\%) } & \multirow[b]{2}{*}{$\mathrm{HV}(\%)$} & \multirow[b]{2}{*}{$\mathrm{MC}(\%)$} \\
\hline Tgl & Jam & & & & \\
\hline 11-Jan & $12.00-12.10$ & 480 & 25,21 & 3,75 & 71,04 \\
\hline 12-Jan & $16.00-16.10$ & 462 & 33,55 & 3,46 & 62,99 \\
\hline 13-Jan & $13.00-13.10$ & 452 & 28,32 & 4,42 & 67,26 \\
\hline 14-Jan & $20.00-20.10$ & 520 & 25,96 & 0,77 & 73,27 \\
\hline 15-Jan & $12.00-12.10$ & 521 & 24,57 & 3,07 & 72,36 \\
\hline 16-Jan & $07.00-07.10$ & 478 & 24,69 & 2,51 & 72,80 \\
\hline 18-Jan & $16.00-16.10$ & 478 & 22,18 & 3,77 & 74,06 \\
\hline 19-Jan & $17.00-17.10$ & 444 & 25,45 & 2,70 & 71,85 \\
\hline 20-Jan & $20.00-20.10$ & 457 & 26,04 & 1,09 & 72,87 \\
\hline 21-Jan & $19.00-19.10$ & 466 & 26,39 & 0,86 & 72,75 \\
\hline 22-Jan & $20.00-20.10$ & 470 & 23,40 & 0,85 & 75,74 \\
\hline 23-Jan & $20.00-20.10$ & 514 & 25,68 & 1,75 & 72,57 \\
\hline
\end{tabular}

Sumber : Data Lapangan

Hasil perhitungan Volume kendaraan berdasarkan waktu dilakukan di 2 lokasi 
berbeda selama 12 hari,dilihat pada Tabel.3. bahwa tingkat Volume Kendaraan yang paling tinggi terjadi pada hari Jumat tanggal 15 Januari 2016 pukul 12.00-12.10.

Hitungan volume kendaraan pada Tabel 3. Kolom 5:

Qtotal kendaraan per-jam $=L V+H V+M C=\underline{521 \mathrm{kend} / \mathrm{jam}}$

$P_{L V}=\frac{L V}{Q_{\text {totkend /jam }}} x(100 \%)=\underline{24,56 \%}$

$P_{H V}=\frac{H V}{Q_{\text {totkend /jam }}} x(100 \%)=\underline{3,07 \%}$

$P_{M C}=\frac{M C}{Q_{\text {totalkend /jam }}} x(100 \%)=\underline{72,36 \%}$

Perhitungan Kecepatan Rata-Rata Kendaraan

Data kecepatan yang didapatkan dilapangan setelah pengamatan selama periode waktu 10 menit di analisis sehingga didapat kecepatan dari masing-masing kendaraan bermotor serta kecepatan rata-rata kendaraan yang melintas pada ruas Jalan Ahmad Yani. Perhitungan kecepatan ruang tiap jenis dilakukan dengan catatan bahwa angka $50 \mathrm{~m}$ adalah jarak tempuh kendaraan (d) yang di survei, $\left(\mathrm{t}_{i}\right)$ adalah waktu yang di butuhkan untuk melintasi jarak $50 \mathrm{~m}$ dalam detik, sedangkan nilai (n) adalah jumlah dari banyaknya kendaraan dalam perhitungan volume kendaraan. Dari data yang didapatkan kemudian di konversi nilai satuan $\mathrm{m} / \mathrm{dtk}$ menjadi $\mathrm{km} / \mathrm{jam}$.

Tabel 4. Puncak Hasil Perhitungan Kecepatan KendaraanTertinggi

\begin{tabular}{|c|c|c|c|}
\hline \multicolumn{2}{|c|}{ Waktu } & \multirow{2}{*}{$\begin{array}{c}\text { Jarak } \\
(\mathrm{m})\end{array}$} & \multirow{2}{*}{$\begin{array}{c}\text { V Rata-Rata } \\
\text { (km/jam) }\end{array}$} \\
\hline $\mathrm{Tgl}$ & Jam & & \\
\hline 11-Jan & $13.00-13.10$ & 50 & 40,35 \\
\hline 12-Jan & $08.00-08.10$ & 50 & 49,47 \\
\hline 13-Jan & $20.00-20.10$ & 50 & 52,03 \\
\hline 14-Jan & $19.00-19.10$ & 50 & 58,43 \\
\hline 15-Jan & $08.00-08.10$ & 50 & 49,40 \\
\hline 16-Jan & $07.00-07.10$ & 50 & 50,23 \\
\hline 18-Jan & $19.00-19.10$ & 50 & 39,04 \\
\hline
\end{tabular}

\begin{tabular}{|c|c|c|c|}
\hline 19-Jan & $19.00-19.10$ & 50 & 38,14 \\
\hline 20-Jan & $16.00-16.10$ & 50 & 34,97 \\
\hline 21-Jan & $08.00-08.10$ & 50 & 39,71 \\
\hline 22-Jan & $19.00-19.10$ & 50 & 38,27 \\
\hline 23-Jan & $12.00-12.10$ & 50 & 37,30 \\
\hline 6-Feb & $12.00-12.10$ & 50 & 53.51 \\
\hline
\end{tabular}

Sumber : Data Lapangan

Hasil perhitungan kecepatan kendaraan berdasarkan waktu dilakukan di 2 lokasi berbeda selama 12 hari,dilihat pada Tabel.4. bahwa tingkat kecepatan Kendaraan yang paling tinggi terjadi pada hari Kamis tanggal 14 Januari 2016 pukul 19.00-19.10.

Hitungan kecepatan ruang tiap jenis pada Tabel 4 kolom 4:

Interval Waktu 19.00-19.10 (persamaan 3) Kendaraan Ringan ( LV)

$\mu_{\mathrm{s}}=\left(\frac{3,6 \times n \times d}{\sum_{l=1}^{n} t_{i}}\right)=\left(\frac{3,6 \times 10 \times 50}{10 \times 5,29}\right)=42,76 \mathrm{~km} / \mathrm{jam}$

Kendaraan Berat ( HV)

$\mu_{\mathrm{s}}=\left(\frac{3,6 \times n \times d}{\sum_{l=1}^{n} t_{i}}\right)=\left(\frac{3,6 \times 5 \times 50}{5 \times 5,56}\right)=42,06 \mathrm{~km} / \mathrm{jam}$

Sepeda Motor (MC)

$\mu_{\mathrm{s}}=\left(\frac{3,6 \times n \times d}{\sum_{l=1}^{n} t_{i}}\right)=\left(\frac{3,6 \times 20 \times 50}{20 \times 3,51}\right)=63,72 \mathrm{~km} / \mathrm{jam}$

- Hitungan kecepatan rata-rata kendaraan pada Tabel.4 kolom 4:

Interval Waktu 19.00-19.10 (persamaan 4)

$$
\begin{gathered}
V=\frac{(V L V \cdot n L V)+(V H V \cdot n H V)+(V M C \cdot n M C)}{n L V+n H V+n M C} \\
V=\left(\frac{(42,76 \times 10)+(42,06 \times 5)+(63,72 \times 20)}{10+5+20}\right)=58,43 \mathrm{~km} / \mathrm{jam}
\end{gathered}
$$

\section{Perhitungan Tingkat Kebisingan}

Dari hasil penelitian tingkat kebisingan kendaraan, puncak tingkat kebisingan kendaraan tertinggi yang melintas di area Jalan Ahmad Yani dapat dilihat pada tabel berikut. 
Tabel 5. Puncak Hasil Perhitungan Tingkat Kebisingan KendaraanTertinggi

\begin{tabular}{|c|c|c|}
\hline \multicolumn{2}{|c|}{ Waktu } & $\begin{array}{c}\text { Leq Hitung } \\
\text { (dbA) }\end{array}$ \\
\hline 11-Jan & Jam & 68,36 \\
\hline 12-Jan & $12.00-13.10$ & 65,28 \\
\hline 13-Jan & $19.00-19.10$ & 64,78 \\
\hline 14-Jan & $19.00-19.10$ & 65,22 \\
\hline 15-Jan & $20.00-20.10$ & 65,23 \\
\hline 16-Jan & $17.00-17.10$ & 68,13 \\
\hline 18-Jan & $13.00-13.10$ & 66,50 \\
\hline 19-Jan & $20.00-20.10$ & 64,93 \\
\hline 20-Jan & $19.00-19.10$ & 64,68 \\
\hline 21-Jan & $07.00-07.10$ & 65,82 \\
\hline 22-Jan & $17.00-17.10$ & 65,77 \\
\hline 23-Jan & $20.00-20.10$ & 65,37 \\
\hline Sumber $:$ Data Lapangan
\end{tabular}

Sumber : Data Lapangan

Hasil perhitungan tingkat kebisingan kendaraan berdasarkan dilakukan di 2 lokasi berbeda selama 12 hari,dilihat pada Tabel.5. bahwa tingkat kebisingan Kendaraan yang paling tinggi terjadi pada hari senin tanggal 11 Januari 2016 pukul 13.00-13.10.

- Hitungan nilai $\mathrm{L}_{\text {eq }}$ pada Tabel.5. kolom 1 :

$$
\begin{aligned}
L_{e q}=10 \log \left[\left(\frac{1}{120} \times 10^{\frac{70.36}{10}}\right)+\left(\frac{1}{120} \times 10^{\frac{80.81}{10}}\right)+\left(\frac{1}{120} \times 10^{\frac{79.83}{10}}\right)\right. \\
+\left(\frac{1}{120} \times 10^{\frac{80.39}{10}}\right)+\left(\frac{1}{120} \times 10^{\frac{81.96}{10}}\right) \\
+\left(\frac{1}{120} \times 10^{\frac{79.28}{10}}\right)+\left(\frac{1}{120} \times 10^{\frac{80.60}{10}}\right) \\
+\left(\frac{1}{120} \times 10^{\frac{74.69}{10}}\right)+\left(\frac{1}{120} \times 10^{\frac{77.67}{10}}\right) \\
\left.+\left(\frac{1}{120} \times 10^{\frac{75.48}{10}}\right)\right]=68,36 \mathrm{dBA}
\end{aligned}
$$

- Hitungan BNL pada Tabel.4. Kolom 7:

$$
\begin{aligned}
L_{e q} & =42.2+10 \log Q_{\text {total kendaraan }} \\
& =42.2+10 \log (432) \\
& =68,55 \mathrm{dBA}
\end{aligned}
$$

\section{Hasil Penelitian Tingkat Kebisinngan dan perbandingannya dengan Standar Baku Mutu menurut KepMen No.48/MENLH/11/1996}

Penelitian dilakukan selama 12 hari, dengan nilai tertinggi selama 7 hari untuk waktu siang dan tertinggi 5 hari untuk waktu malam. Hal ini menunjukkan bahwa 58,33\% polusi suara yang dihasilkan pada ruas Jalan Ahmad Yani terjadi pada waktu siang hari dan $41,67 \%$ terjadi pada malam hari.Tingkat kebisingan dalam $\mathrm{L}_{\mathrm{eq}}$ hitung paling tinggi yang terjadi di ruas Jalan Ahmad Yani sebesar 68,12 dBA yang terjadi pada Lokasi 2 (dua) pada hari Sabtu 16 Januari 2016 pukul 17.00-17.10. Sedangkan yang paling rendah yaitu sebesar 62,43 dBA yang terjadi pada Lokasi 1 (satu) pada hari Jumat 22 Januari 2016 pada pukul 08.00-08.10.Tingkat kebisingan dalam perhitunngan dengan pendekatan rumus $\mathrm{BNL}$ yang paling tinggi terjadi di ruas Jalan Ahmad Yani sebesar 69,36 dBA yang terjadi pada Lokasi 1 (satu) pada hari Jumat 15 Januari 2016 pukul 12.00-12.10. Sedangkan yang paling rendah yaitu sebesar 66,77 dBA yang terjadi pada lokasi 2 (dua) pada hari kamis 14 Januari 2016 pukul 08.00-08.10.Dari hasil penelitian menyeluruh menunjukkan bahwa tingkat kebisingan pada ruas Jalan Ahmad Yani dengan 2 (dua) titik lokasi yang berbeda telah melampaui baku mutu tingkat kebisingan dengan rentang tingkat kebisingan di lapangan antara 60-80 dBA.

Menurut Keputusan Menteri Negara Lingkungan Hidup No. KEP48/MENLH/11/1996 tingkat kebisingan untuk kawasan untuk pemukiman dan perumahan, rumah sakit, tempat ibadah dan sarana pendidikan yaitu sebesar 58 dBA ( 55 $\mathrm{dBA}+$ toleransi $3 \mathrm{dBA}$ ).

\section{PENUTUP}

\section{Kesimpulan}

Adapun kesimpulan dari hasil penelitian ini diantaranya :

1. Tingkat kebisingan dalam $\mathrm{L}_{\mathrm{eq}}$ hitung paling tinggi yang terjadi di ruas Jalan Ahmad Yani sebesar 68,12 dBA yang terjadi pada Lokasi 2 (dua) pada hari Sabtu 16 Januari 2016 pukul 17.0017.10.Tingkat kebisingan dalam perhitunngan dengan pendekatan rumus BNL yang paling tinggi terjadi di ruas Jalan Ahmad Yani sebesar 69,36 dBA yang terjadi pada Lokasi 1 (satu) pada hari Jumat 15 Januari 2016 pukul 12.00-12.10 Dengan nilai kebisingan yang demikian 
maka ruas Jalan Ahmad Yani termasuk dalam Zona D yaitu zona untuk lingkungan industri, pabrik, stasiun kereta api dan terminal bus yang tingkat kebisingannya berkisar 60-70 dB.

2. Berdasarkan nilai kebisingan yang diperoleh ,maka tingkat kebisingan lalu lintas kendaaraan pada Jalan Ahmad Yani dengan 2 (dua) titik lokasi berbeda telah melampaui standar baku mutu yang di tetapkan Menurut Keputusan Menteri Negara Lingkungan Hidup No. KEP48/MENLH/11/1996 untuk kawasan perumahan, rumah sakit, tempat ibadah dan sarana pendidikan.

3. Faktor penyebab kebisingan lalu lintas dari Jalan Ahmad Yani bersumber dari kondisi jalan yang terdapat tanjakan, suara klakson angkutan umum, laju kendaraan, serta komposisi kendaraan seperti knalpot racing, pembakaran mesin, pergesekan ban, dan suara rem angin.

\section{Saran}

1. Untuk penelitian selanjutnya, perlu adanya perhitungan tentang peredam bunyi (noise barrier) terhadap tingkat kebisingan yang terjadi pada lingkungan ruas jalan yang akan di tinjau.

2. Perlu adanya sosialisasi terhadap masyarakat yang tinggal disekitar jalan raya yang tingkat kebisingannya tinggi mengenai bahaya kebisingan sehingga dapat dilakukan tindakan mitigasi sebagai solusi untuk penanganan masalah kebisingan seperti penanaman pohon atau pembuatan peredam kebisingan (noise barrier).

\section{DAFTAR PUSTAKA}

Anonim. 1996. Keputusan Menteri Negara Lingkungan Hidup Nomor : KEP48/MENLH/11/1996 tentang Baku Tingkat Kebisingan.

Anonim. 1999. Keputusan Menteri Tenaga Kerja Nomor : Kep-51/MEN/1999 tentang
Nilai Ambang Batas Faktor Fisik di Tempat Kerja.

Doelle L.L. (1993). Akustik Lingkungan (Lea Prasetio). Jakarta : Penerbit Erlangga.

Leonard F., (2014). Analisa Tingkat Kekuatan Bunyi Klakson Kendaraan Ringan (Angkutan Umum Pete-Pete) di Kota Makassar, Universitas Hasanuddin Makassar, Makassar

Ramli M.I., Hustim M., Ariani U.,(n.d) Analisis Tingkat Kebisingan Pada Kawasan Perbelanjaan (Mall) di Kota Makassar dan Dampaknya Terhadap Lingkungan. Jurnal, Universitas Hasanuddin : Makassar.

Sam F. (2012). Studi Model Hubungan Karakteristik Lalu Lintaas Dengan Tingkat Kebisingan Kendaraan Pada Ruas Jalan Tol Ir.Sutami Makassar. Universitas Hasanuddin Makassar

Syaiful (n.d.) Studi Kasus Tentang Lalu Lintas Kendaraan Bermotor Hubungannya dengan Geometri Jalan Akibat Suara yang Ditimbulkannya di Kota Besar Pulau Jawa, Universitas Brawijaya Malang, Malang

Yadat T., (2014) Studi Power Level Kebisingan Kendaraan Ringan di Kota Makassar. Universitas Hasanuddin Makassar, Makassar

Yusniar W. O. (2014) Analisa Kebisingan Lalu Lintas Kendaraan di Jalan Jendral Sudirman Kota Sorong, Universitas Muhammadiyah Sorong , Kota Sorong 